\title{
The growth of rural criminology: introduction to the special issue
}

\author{
Meghan E. Hollis ${ }^{1}$. Shannon Hankhouse ${ }^{2}$
}

Published online: 27 May 2019

(c) Springer Nature Limited 2019

There is increased attention to the field of rural criminology in recent years. There is now a rural criminology listserv that brings together scholars with shared interests and shared challenges. There have been attempts at developing a journal focused exclusively on rural criminology, and scholars are increasingly likely to label themselves "rural criminologists." Most recently, the development of the Division of Rural Criminology at the American Society of Criminology highlights the increased attention and importance of this area as a focused area of scholarship.

Focused scholarship on rural criminology is long overdue. A minority of scholars have worked in this area in the past, and it has not received much attention by mainstream criminologists. The study of criminology is the study of urban crime and criminality historically. This is unfortunate as much of the world's land and population is not concentrated in urban areas. According to the 2016 American Community Survey (www.census.gov), for example, land area in the USA is 97\% rural. This area contains only $19.3 \%$ of the American population, however. This indicates that the majority of American criminology (focused on American urban areas and institutions) ignores $97 \%$ of the country's land area and $19.3 \%$ of the population. Qualitative and quantitative evaluations comparing the rural and urban populations indicate substantial differences between these populations. Unfortunately, our knowledge about disparities in crime, victimization experiences, criminal justice system activities and treatment, and other areas of criminological concern is severely limited.

In the UK, a land cover atlas published in 2017 indicates that only $6 \%$ of land in the UK is "built on." Over half of the country was classified as pasture or arable land. There are clusters of urbanized area displayed on the maps (www.sheff ield.ac.uk/news/nr/land-cover-atlas-uk-1.744440), but these are surrounded by large areas of rural land. An examination country-by-country reveals that many

Meghan E. Hollis

Meghan.hollis@ronininstitute.org

Shannon Hankhouse

hankhouse@tarleton.edu

1 Ronin Institute, Montclair, USA

2 Tarleton State University, Stephenville, USA 
westernized countries have a population that is around $20 \%$ rural with a dominant land area that is classified as rural or non-metropolitan.

Of course, this focuses on westernized and urbanized countries. Many of the world's countries are dominated by rural landscapes and lack significant urban centers as seen in the Western nations. An examination of rural population by country in the World Atlas (www.worldatlas.com/articles/working-on-the-land-of-theworlds-s-major-rural-populations.html) indicates that the top 12 most rural nations (by population) are over $80 \%$ rural. These countries include Trinidad and Tobago (91.45\% of population in rural areas), Burundi (88.24\%), Papua New Guinea (87.02\%), Liechtenstein (85.70\%), Uganda (84.23\%), Malawi (83.90\%), Nepal (81.76\%), Sri Lanka (81.68\%), Niger (81.53\%), South Sudan (81.41\%), Ethiopia $(80.97 \%)$, and Samoa $(80.74 \%)$. Another trend is revealed as the remaining 13 nations in the top 25 most rural nations by population are examined: Many of them are in Africa and Asia. The countries included in this list are also largely missing from mainstream criminology.

Criminology is predominately the study of westernized and urbanized societies. The lack of research examining rural and agrarian cultures and countries is a significant gap in the criminological literature at this time. This raises important questions about the generalizability of criminological research beyond urbanized and Western societies. For example, Lemieux's (2011) analysis of elephant poaching in Africa provides a very different take on rural crime, despite poaching being a concern in the West. Additionally, these gaps highlight important information missing from the knowledge base on criminal justice systems. We simply do not know how justice systems operate in other contexts. It is possible that we are missing important interventions and system components that are highly successful for the prevention of crime through a focus solely on countries that are like our own. These limitations continue to be reflected in the articles received and selected for the current special issue.

\section{The current volume}

The current volume highlights research from the USA, England, and Canada. The papers in this volume also have an uneven focus. The first, by Kaylen et al., compares assault trends over time between rural, suburban, and urban areas in the USA. The next two papers address crime and space (Shukla et al., and Smith). The fourth paper, by Smith and Byrne, focuses on rural crime in England, while the final paper, by Griffiths, focuses on policing in rural areas. The focus of this work continues to be on Western democracies and traditional theoretical approaches to the study of crime and the criminal justice system.

Kaylen et al. examine UCR and NCS/NCVS data from 1988 to 2005 to compare aggravated assault rate trends in rural, suburban, and urban areas. They found considerable differences in trends for urban and non-urban areas. Unfortunately, the focus remains a comparison of rural areas to an urban benchmark and does not expand to attempt to better understand rural crime as a topic of independent study. This is an important step in better understanding rural crime (establishing that there 
is a difference between rural and urban crime patterns) and highlights a need for a targeted focus on rural crime patterns and what makes them different.

Smith's paper examines the concept of "fortress farm" through the lens of defensible space. This study focuses on farms in the UK and the "fortress farm" concept advocated by the National Farmers Union. Smith applies the concept of defensible space to better understand crime prevention and attempts to design out crime on farms. This important paper highlights the need for crime prevention research to expand to understand the unique challenges and types of crime experienced in rural areas.

The work of Shukla and colleagues, in contrast, highlights the interaction of crime and place to study crime and policing in non-metropolitan areas of the USA. They examined six non-metropolitan law enforcement agencies in Oklahoma in the USA through qualitative interviews and field observations. This paper highlights some of the unique challenges that rural police agencies face and emphasize the importance of further study of smaller police agencies that are not located in urban centers.

Smith and Byrne scan the horizon of crime threats in rural England. They found a number of emerging crime trends that are impacting rural communities in England. This work has important implications for future study of crime in England, where, as in the USA, research has focused on urban centers and neglected the different experiences and needs of those living in rural areas.

Finally, Griffiths examined policing in communities in Northern Canada. This research looked at the intersection of rural criminology and the presence of indigenous populations. This intersectional focus on indigenous people's experiences in rural areas makes an important contribution to the current volume. The combination of rurality, high concentration of indigenous populations, and challenging weather and terrain conditions in this area creates an interesting challenge for policing of local communities.

The current volume is the product of several years of targeted work and collaboration. This volume began with a conversation between Professor Rob Mawby and Dr. Meghan Hollis about a potential special issue. Dr. Joe Donnermeyer joined us in the early stages to help solicit potential papers and to advertise the special issue. Dr. Donnermeyer's contributions to this issue continued in the form of helping Dr. Hollis review and edit papers. In the end, Dr. Hankhouse joined the editorial group when Dr. Hollis took a new job outside of academia. It is her efforts and support that have allowed this volume to be successfully completed. This journey has highlighted many strengths in the current rural criminology scholarship as well as potential next steps to expand rural criminological research in the future. The trio of editors for this volume continue to work to advance this field as an important area of inquiry.

\section{The future of rural criminology}

When we originally conceptualized this volume, we had high hopes that we would see greater representation of theoretical approaches, different subjects of study, and different countries and types of countries represented. The absence of critical 
criminological approaches from this volume is notable, for example. Also notable is the absence of scholarship focused on countries that are more rural in population and in land area. Agrarian societies are likely to have different approaches to criminal justice, crime, and the administration of justice as can be seen from a review of the history of countries such as the USA and England (see, e.g., Ackroyd 2011 for an early history of England).

It is also concerning that there is a gap in scholarship on the rural criminal justice system and criminal justice processes. How do rural court systems function? How are they different from those in urbanized areas? There is a need for research to better understand such concerns as access to bail, indigent defense, rural jails and detainment, pretrial services and treatment, legal representation (both quality and access) in rural areas, and the structure and actions of rural police departments or other law enforcement entities active in these areas. As Mawby (2011) noted, the difference in size and degree of isolation between the rural in Australia and the UK imposes different constraints on policing and the management of the police, but there is no comparable discussion of court processes. Additionally, how does the choice to locate prisons (particularly in the USA) in rural areas impact the local communities? There are so many areas of interest left unexplored at this time in rural criminology.

The future of rural criminological research is both daunting and exciting. There are many areas available for inquiry that have never been explored before. The development of the Division of Rural Criminology and the emergence of volumes dedicated to the study of rural criminology (such as this one) provide important first steps. Now it is essential that rural criminologists move beyond the traditions of criminology embedded in the study of urban areas and proceed with an open mind to better explore and understand a previously ignored area of inquiry. This might warrant a great deal of creative intellectual activity as new theories need to be explored rather than trying to force urban theories of crime to bend to explain rural concerns. This is a call for new areas of study and exploration of new topics in new places. The future of rural criminology presents many exciting opportunities and challenges, and it is our hope that criminological scholars will seize these opportunities to expand our understanding of crime and the justice system through a more global lens.

\section{References}

Ackroyd, P. 2011. Foundation: The History of England from Its Earliest Beginnings to the Tudors. New York: Thomas Dunne Books.

Lemieux, A.M. 2011. Policing Poaching and Protecting Pachyderms: Lessons Learned from Africa's Elephants. In Rural Policing and Policing the Rural, ed. R.I. Mawby and R. Yarwood, 183-192. Aldershot: Ashgate.

Mawby, R.I. 2011. Rural Police: A Comparative Overview. In Rural Policing and Policing the Rural, ed. R.I. Mawby and R. Yarwood, 11-22. Aldershot: Ashgate.

Publisher's Note Springer Nature remains neutral with regard to jurisdictional claims in published maps and institutional affiliations. 